\title{
MÉTODOS DE DETERMINAÇÃO DE CÁLCIO E MAGNÉSIO TROCÁVEIS E ESTIMATIVA DO CALCÁRIO RESIDUAL EM UM LATOSSOLO SUBMETIDO À APLICAÇÃO DE CALCÁRIO E GESSO EM SUPERFÍCIE ${ }^{(1)}$
}

\author{
Rogério Peres Soratto $^{(2)} \&$ Carlos Alexandre Costa Crusciol ${ }^{(3)}$
}

\begin{abstract}
RESUMO
A determinação da fração do calcário remanescente no solo ("calcário residual"), em área onde foi realizada aplicação de calcário em superfície, sem incorporação, na implantação do sistema plantio direto, pode ser uma ferramenta importante para auxiliar na definição do momento em que se faz necessária a reaplicação de calcário. Nesse sentido, os objetivos deste trabalho foram avaliar: quais os teores de Ca e Mg trocáveis, extraídos por percolação com solução de $\mathrm{KCl}$ e resina trocadora de íons; a quantidade do calcário aplicado que ainda não havia reagido no solo, mediante a determinação dos teores de Ca e Mg não-trocáveis; e qual a influência do gesso nos teores de Ca e Mg trocáveis e na dissolução do calcário, 18 meses após a aplicação em superfície. O experimento foi realizado em um Latossolo Vermelho distroférrico, em Botucatu (SP). O delineamento experimental foi de blocos casualizados com parcelas subdivididas e quatro repetições. Nas parcelas, foram aplicadas quatro doses de calcário dolomítico (0, $1.100,2.700$ e $4.300 \mathrm{~kg} \mathrm{ha}^{-1}$, com PRNT = 71,2 \%, e nas subparcelas, duas doses de gesso agrícola (0 e $\left.2.100 \mathrm{~kg} \mathrm{ha}^{-1}\right)$. O calcário e o gesso foram aplicados em superfície, sem incorporação. Houve alta correlação na determinação de Ca e Mg trocável entre os métodos de percolação com solução de $\mathrm{KCl}$ e resina trocadora de íons. A extração pelo método da resina trocadora de íons superestimou os teores de Ca e Mg trocáveis em solo com recente aplicação de calcário em superfície. A aplicação de gesso em superfície reduziu a dissolução do calcário na camada superficial (0$0,10 \mathrm{~m}$ ). Os teores de Ca e Mg não-trocáveis podem ser utilizados para estimar a quantidade de calcário residual no solo.
\end{abstract}

Termos de indexação: calagem, gessagem, aplicação em superfície, calcário remanescente, cátion trocável.

\footnotetext{
(1) Parte da Tese de Doutorado do primeiro autor apresentada à Faculdade de Ciências Agronômicas, Universidade Estadual Paulista - FCA/UNESP. Recebido para publicação em março de 2007 e aprovado em outubro de 2007.

(2) Professor Assistente Doutor do Departamento de Produção Vegetal, Faculdade de Ciências Agronômicas, Universidade Estadual Paulista - FCA/UNESP. Campus de Botucatu, Caixa Postal 237, CEP 18603-970 Botucatu (SP). E-mail: soratto@fca.unesp.br

(3) Professor Adjunto do Departamento de Produção Vegetal, FCA/UNESP. Bolsista do CNPq. E-mail: crusciol@fca.unesp.br
} 


\title{
SUMMARY: METHODS FOR DETERMINING SOIL EXCHANGEABLE CALCIUM AND MAGNESIUM AND RESIDUAL LIME IN AN OXISOL SUBMITTED TO SURFACE APPLICATION OF LIME AND PHOSPHOGYPSUM
}

\begin{abstract}
The determination of the non-reacted lime fraction in the soil ("residual lime") after initial surface application of lime without incorporation in no-tillage systems can be important to determine when lime reapplication is necessary. The objective of this study was to evaluate: the exchangeable Ca and $\mathrm{Mg}$ contents, extracted by percolation with a $\mathrm{KCl}$ solution or ion exchange resin; the quantity of applied lime that had not reacted in the soil, determined based on the non-exchangeable $\mathrm{Ca}$ and $\mathrm{Mg}$ contents; and the effect of the phosphogypsum on the exchangeable Ca and $\mathrm{Mg}$ contents and the surface lime dissolution, 18 months after application. The experiment was carried out on a Haplorthox (Oxisol) in Botucatu County, São Paulo State, Brazil. It was adopted a randomized complete block design in a split-plot scheme, with four replications. The plots were composed by four dolomitic limestone levels $\left(0 ; 1,100 ; 2,700\right.$; and 4,300 $\left.\mathrm{kg} \mathrm{ha}^{-1}\right)$ with Neutralization Power = $84.3 \%$ and Reactivity $=84.5 \%$. The subplots consisted of two phosphogypsum levels $(0$ and $\left.2,100 \mathrm{~kg} \mathrm{ha}^{-1}\right)$. Both lime and phosphogypsum were surface-applied, without incorporation. There was a high correlation between exchangeable Ca and $\mathrm{Mg}$ determined through percolation of a $\mathrm{KCl}$ solution and that by ion exchange resin methods. The ion exchange resin method overestimated exchangeable Ca and $\mathrm{Mg}$ contents in soil with recent lime surface application. Surface application of phosphogypsum reduced lime dissolution in the surface layer $(0-0.10 \mathrm{~m})$. The non-exchangeable Ca and $\mathrm{Mg}$ contents may be used to estimate the amount of soil residual lime.
\end{abstract}

Index terms: phosphogypsum, surface application, cation, liming, residual lime, exchangeable cation.

\section{INTRODUÇÃO}

O sistema plantio direto é uma das melhores alternativas para manutenção da sustentabilidade dos recursos naturais na utilização agrícola dos solos, constituindo uma eficiente prática para o controle da erosão e para o acúmulo superficial de matéria orgânica em virtude da não-mobilização, propiciando maior disponibilidade de água e nutrientes às plantas (Muzilli, 1981; Balbino et al., 1996). Assim, atualmente há interesse na implantação do sistema plantio direto sem incorporação prévia de corretivos, desde que não haja limitações físicas para o crescimento radicular das culturas (Lima, 2004; Soratto, 2005). Contudo, a eficiência da aplicação do calcário superficialmente, sem incorporação, em particular na correção da acidez do subsolo, ainda é controvertida (Caires et al., 2000).

Vários mecanismos interferem na eficiência da calagem superficial em corrigir a acidez subsuperficial, como o deslocamento mecânico de partículas de calcário através de canais formados por raízes mortas, mantidos intactos em razão da ausência de preparo do solo (Amaral et al., 2004), e a lixiviação de sais, mediante a presença de moléculas orgânicas carreadoras, originadas de resíduos orgânicos ou adubos verdes (Miyazawa et al., 2000), ou de íons nitrato e sulfato (Raij et al., 1988).
A profundidade de ação da calagem em superfície na correção da acidez do solo varia de acordo com a dose e granulometria do produto, forma de aplicação, tipo de solo, condições climáticas, sistema de cultivo e tempo decorrido da aplicação (Oliveria \& Pavan, 1996; Caires et al., 1999, 2000, 2003, 2005; Mello et al., 2003). Porém, tem sido verificado que a ação do calcário aplicado em superfície, sem incorporação, é restrita à camada superficial $(0-0,10 \mathrm{~m})$, especialmente nos primeiros anos de cultivo (Caires et al., 1998; Pöttker \& Ben, 1998; Barizon, 2001). Mesmo assim, constatase que a maioria dos produtores vem adotando a prática de reaplicar o calcário sem incorporá-lo ao solo, visando a vantagens como a manutenção de atributos estruturais do solo, controle da erosão e economia com operações mecanizadas.

A aplicação de gesso agrícola em superfície é apontada como alternativa para a melhoria do ambiente radicular, compensando o reduzido efeito do calcário no subsolo (Caires et al., 2003). O gesso agrícola $\left(\mathrm{CaSO}_{4} \cdot 2 \mathrm{H}_{2} \mathrm{O}\right)$ aplicado na superfície do solo movimenta-se ao longo do perfil sob a influência da percolação de água (Caires et al., 1999), obtendo-se aumento no suprimento de Ca e redução da toxidez de Al no subsolo em menor tempo (Caires et al., 1999, 2003).

Em solos ácidos manejados no sistema plantio direto, fatores como o maior teor de matéria orgânica, 
a maior concentração de nutrientes e a maior umidade nas camadas superficiais podem proporcionar a obtenção de altas produtividades das culturas, mesmo em condições de alta acidez $\left(\mathrm{pH} \mathrm{CaCl} \mathrm{Cl}_{2} 4,5\right)$ (Caires et al., 1998, 2000, 2005). Apesar disso, em muitos casos a calagem pode ser necessária. O cálculo da necessidade de calagem, com base na análise química do solo, e a freqüência de aplicação de calcário na superfície, sem incorporação, requer critérios adequados, pois a recomendação baseada nos mesmos critérios utilizados no sistema convencional, com incorporação ao solo, pode superestimar a dose de calcário a ser utilizada (Nolla et al., 2005), e doses excessivas de calcário, concentradas na superfície do solo, podem ocasionar redução na absorção de Zn e de $\mathrm{Mn}$, em decorrência do aumento do $\mathrm{pH}$ nas camadas superficiais do solo (Caires \& Fonseca, 2000; Caires et al., 2003; Miranda et al., 2005).

Os critérios para recomendação de calagem incluem a decisão de aplicar ou não corretivo de acidez (necessidade de calagem) e a definição da dose de calcário a ser aplicada para atingir objetivo especificado, ou seja, elevação do $\mathrm{pH}$ ou da saturação por bases em um nível predeterminado (Nolla \& Anghinoni, 2006). $\mathrm{O}$ teor de $\mathrm{Al}$ trocável, a acidez potencial $(\mathrm{H}+\mathrm{Al})$, o índice $\mathrm{SMP}$, o $\mathrm{pH}$ e as saturações por bases e por $\mathrm{Al}$ são características do solo que podem ser utilizadas para estimativa da necessidade de sua calagem (Raij et al., 1996; CFSEMG, 1999; CQFSRS/SC, 2004; Nolla \& Anghinoni, 2004; Sousa \& Lobato, 2004).

Nos Estados do Rio Grande do Sul e Santa Catarina, os critérios adotados para definir se há ou não necessidade de calagem para o sistema plantio direto são: aplicar ou reaplicar calcário sempre que o $\mathrm{pH}$ (água) for menor que 5,5 e, ou, a saturação por bases menor que $65 \%$, na camada de $0-0,10 \mathrm{~m}$. No caso da aplicação ou reaplicação de calcário, quando o sistema já estiver com mais de cinco anos (consolidado), elas podem ser superficiais. A dose é estimada para elevar o pH até 5,5, na camada de 0-0,10 m (CQFSRS/SC, 2004). Para Nolla \& Anghinoni (2006), deve-se adotar o seguinte critério de tomada de decisão para realização da calagem na cultura da soja em plantio direto consolidado: pH (água) de 5,5 ou pH $\left(\mathrm{CaCl}_{2}\right)$ de 4,5 e saturação por bases $62 \%$, na camada de $0-0,10 \mathrm{~m}$.

No Paraná, Caires et al. (2000) propuseram que o cálculo da necessidade de calagem em superfície, no sistema plantio direto, deve ser realizado mediante a elevação da saturação por bases a $65 \%$, em amostra de solo coletada na profundidade de $0-0,20 \mathrm{~m}$. Todavia, a calagem superficial somente deve ser recomendada para solo com $\mathrm{pH}\left(\mathrm{CaCl}_{2}\right)$ inferior a 5,6 ou saturação por bases inferior a $65 \%$, na camada de $0-0,05 \mathrm{~m}$

Assim, ainda faltam informações/ferramentas suficientes para definir os critérios a serem utilizados para recomendação da reaplicação de calagem no sistema plantio direto consolidado ou em fase de implantação, sem mobilização do solo.
Nesse sentido, a determinação das frações nãotrocáveis de $\mathrm{Ca}$ e $\mathrm{Mg}$ no solo, que teoricamente representam a fração do corretivo remanescente, que ainda não havia dissolvido no solo ("calcário residual"), descrita por Raij et al. (1982), Quaggio et al. (1982) e Quaggio et al. (1995), aliada às características químicas contidas na análise de fertilidade, poderá ser ferramenta importante para auxiliar na definição do momento em que se faz necessária a reaplicação de calcário no sistema plantio direto (Raij et al., 1982; Quaggio et al., 1982; Lima, 2004). Contudo, ainda faltam estudos para validação do método e sobre a influência de outros fatores, como a dose de calcário utilizada e a combinação com a aplicação de gesso, nos teores de Ca e Mg não-trocáveis no solo, ou seja, na estimativa do calcário residual.

O objetivo do presente trabalho foi verificar, 18 meses após a aplicação de calcário e gesso em superfície, na implantação do sistema plantio direto: quais os teores de $\mathrm{Ca}$ e $\mathrm{Mg}$ trocáveis extraídos por percolação com solução de $\mathrm{KCl}$ e resina trocadora de íons; a quantidade do calcário aplicado que ainda não havia reagido no solo, mediante a determinação dos teores de Ca e Mg não-trocáveis; e qual a influência do gesso nos teores de $\mathrm{Ca}$ e $\mathrm{Mg}$ trocáveis e na dissolução do calcário aplicado em superfície.

\section{MATERIAL E MÉTODOS}

O trabalho foi realizado na Fazenda Experimental Lageado, pertencente à Faculdade de Ciências Agronômicas - Unesp, município de Botucatu, SP, a $48^{\circ} 23^{\prime} \mathrm{W}$ e $22^{\circ} 51^{\prime} \mathrm{S}$, de $765 \mathrm{~m}$. O clima, conforme a classificação de Köppen, é do tipo Cwa, que se caracteriza como tropical de altitude, com inverno seco e verão quente e chuvoso. O solo do local é um Latossolo Vermelho distroférrico, o qual permaneceu dois anos em pousio. Em fevereiro de 2001 foi cultivada soja (safrinha) mediante preparo de solo convencional (uma aração e duas gradagens). Em outubro de 2001, a área experimental foi subsolada e semeou-se guandu (Cajanus cajan (L.) Millsp.), que foi manejado com triturador de palha em 2/10/2002. Em agosto de 2002, foram coletadas amostras nas profundidades de 0-0,20 e 0,20-0,40 m, para realização de análises químicas (Raij et al., 2001) e granulométricas (Embrapa, 1997) (Quadro 1).

$\mathrm{O}$ delineamento experimental utilizado foi em blocos casualizados em esquema de parcelas subdivididas, com quatro repetições. Os tratamentos foram constituídos por quatro doses $(0,1.100,2.700 \mathrm{e}$ $\left.4.300 \mathrm{~kg} \mathrm{ha}^{-1}\right)$ de calcário dolomítico $(23,3 \%$ de $\mathrm{CaO}$, $17,5 \%$ de $\mathrm{MgO}, 0,3,7,3$ e 23,5 \% de partículas retidas nas peneiras $\mathrm{n}-10,20$ e 50, respectivamente, $\mathrm{PN}$ de 84,3 \% e PRNT de 71,2 \%), visando elevar a saturação por bases para 50, 70 e $90 \%$, respectivamente, combinadas com duas doses (0 e $\left.2.100 \mathrm{~kg} \mathrm{ha}^{-1}\right)$ de gesso 
Quadro 1. Características químicas e granulométricas do Latossolo Vermelho distroférrico nas profundidades de $0-0,20$ e $0,20-0,40 \mathrm{~m}$

\begin{tabular}{|c|c|c|c|c|c|c|c|c|c|c|c|}
\hline Profundidade & MO & $\mathrm{pH} \mathrm{CaCl}{ }_{2}$ & $P(r e s i n a)$ & $\mathbf{K}^{+}$ & $\mathrm{Ca}^{2+}$ & $\mathrm{Mg}^{2+}$ & $\mathrm{Al}^{3+}$ & $\mathrm{V}$ & Areia & Silte & Argila \\
\hline $\mathrm{m}$ & $\mathrm{g} \mathrm{dm}^{-3}$ & & $\mathrm{mg} \mathrm{dm}^{-3}$ & 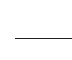 & $-\mathrm{mm}$ & $\mathrm{dm}^{-3}$ & - & $\%$ & 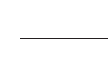 & $\mathrm{g} \mathrm{kg}^{-1}$ & - \\
\hline $0-0,20$ & 20,9 & 4,2 & 9,2 & 1,2 & 14,0 & 5,0 & $-(1)$ & 37 & 545 & 108 & 347 \\
\hline $0,20-0,40$ & 22,3 & 3,9 & 6,0 & 0,2 & 17,6 & 4,8 & 17,9 & 22 & 513 & 127 & 360 \\
\hline
\end{tabular}

(1) Não foi determinado.

agrícola (20\% de Ca e $16 \%$ de S). A dose de gesso foi calculada ( $6 \mathrm{x}$ teor de argila em $\mathrm{g} \mathrm{kg}{ }^{-1}$, na camada de 0,20-0,40 $\mathrm{m}$ de profundidade) de acordo com recomendação de Raij et al. (1996); a área apresentava saturação por $\mathrm{Al}^{3+}$ maior que $40 \%$ na camada de 0,20 0,40 m (Quadro 1), indicando necessidade de correção do subsolo. Nas parcelas, com dimensão de $18,0 \times 5,4 \mathrm{~m}\left(97,2 \mathrm{~m}^{2}\right)$, foram aplicadas as doses de calcário e, nas subparcelas, com dimensão de $9,0 \times 5,4 \mathrm{~m}\left(48,6 \mathrm{~m}^{2}\right)$, as doses de gesso. Foram mantidas distâncias de 8,0 m entre as parcelas dentro de cada bloco e de 3,0 m entre os blocos. Para as avaliações, foram descartadas as bordaduras de $0,5 \mathrm{~m}$ nas extremidades de cada unidade experimental.

A calagem foi realizada sobre os restos culturais de guandu no dia 15/10/2002, nas parcelas em que estava previsto este tratamento. No dia 16/10/2002, realizou-se a aplicação de gesso agrícola em metade de todas as parcelas. O calcário e o gesso foram aplicados superficialmente, sem incorporação ao solo, como o intuito de implantar o sistema plantio direto sem a necessidade de revolver o solo para incorporação de corretivos.

Nas safras de verão dos anos agrícolas de 2002/03 e 2003/04, foram cultivadas na área, respectivamente, as culturas de arroz de terras altas e feijão. A adubação básica, em ambos os cultivos, constituiu-se de $300 \mathrm{~kg} \mathrm{ha}^{-1}$ da fórmula N-P-K 08-28-16 + 4,5\% de $\mathrm{S}+0,5 \%$ de $\mathrm{Zn}$. Após a colheita do arroz, no primeiro ano agrícola, foi semeada aveia-preta (Avena strigosa Schreber), cv Comum, em 30/4/2003, em toda a área experimental. A adubação básica constituiu-se de $200 \mathrm{~kg} \mathrm{ha}^{-1}$ da fórmula N-P-K 10-20-10 + 4,5\% de $\mathrm{S}$. Todas as culturas foram cultivadas no sistema plantio direto, sem preparo do solo.

Foram realizadas amostragens estratificadas do solo aos 18 meses após a aplicação dos corretivos nas camadas de 0-0,05, 0,05-0,10, 0,10-0,20, 0,20-0,40 e $0,40-0,60 \mathrm{~m}$ de profundidade. Foram retiradas aleatoriamente sete amostras simples nas três camadas mais superficiais e quatro amostras simples nas duas camadas mais profundas, na área útil de cada subparcela, para constituir uma amostra composta, sempre na entrelinha da cultura presente na área, com a utilização de trado tipo sonda. As amostras compostas foram secas ao ar e peneiradas (malha de $2 \mathrm{~mm}$ ). Posteriormente, foram realizadas análises para determinação dos teores de $\mathrm{Ca}$ e $\mathrm{Mg}$ trocáveis, extraídos por resina trocadora de íons e pH $\mathrm{CaCl}_{2}$, conforme método proposto por Raij et al. (2001).

A determinação dos teores de Ca e Mg trocáveis, extraídos por percolação com solução $\mathrm{KCl} 1 \mathrm{~mol} \mathrm{~L}^{-1}$, e dos teores de Ca e Mg não-trocáveis do solo, ou seja, a fração dos corretivos que ainda não havia reagido, foram realizadas segundo método descrito por Raij et al. (1982) e Quaggio et al. (1995). Assim, em tubo percolador foram colocados $5 \mathrm{~cm}^{3}$ de solo, entre papéisfiltro, sendo posteriormente percolados $50 \mathrm{~mL}$ da solução de KCl pela amostra (primeira extração). Em uma alíquota de $1 \mathrm{~mL}$ do extrato obtido após a percolação, acrescentaram-se $10 \mathrm{~mL}$ de La 0,1\% e realizaram-se as leituras por espectrofotometria de absorção atômica dos teores de Ca e Mg. Os resultados, depois de descontados os valores da testemunha, que não recebeu calcário e gesso, indicam os teores de Ca e Mg trocáveis no solo, ou seja, a fração dos corretivos aplicados que já havia reagido no solo.

Após a primeira extração, o solo foi transferido para um erlenmeyer e adicionaram-se $15 \mathrm{~mL}$ de $\mathrm{H}_{2} \mathrm{O}+25 \mathrm{~mL}$ de $\mathrm{HCl} 0,8 \mathrm{~mol} \mathrm{~L}^{-1}$. O conjunto foi fervido em chapa aquecedora por $5 \min \left(200^{\circ} \mathrm{C}\right)$. Dessa forma, mediante a fervura do solo, juntamente com a ação do $\mathrm{HCl}$, o corretivo remanescente foi forçado a reagir (rápida dissolução). Na seqüência, após resfriamento, o material foi filtrado (segunda extração); em $1 \mathrm{~mL}$ do extrato foram acrescentados $10 \mathrm{~mL}$ de La $0,5 \%$. A leitura foi realizada por espectrofotometria, determinando-se os teores de Ca e $\mathrm{Mg}$, referentes a valores estimados de Ca e Mg não-trocáveis. Os resultados, depois de descontados os valores da testemunha, que não recebeu calcário e gesso, indicam a fração dos corretivos que ainda não havia reagido no solo (Raij et al., 1982; Quaggio et al., 1995).

É importante salientar que as determinações também foram realizadas no solo coletado nas parcelas que não receberam calcário e gesso, visando separar o Ca e o Mg proveniente dos corretivos, do que foi suprido pelo solo, no caso dos elementos trocáveis, e do proveniente dos minerais no caso dos elementos nãotrocáveis. 
Os dados foram submetidos à análise de variância. As médias de gesso foram comparadas pelo teste $\mathrm{F}$, sendo apresentados os resultados do efeito do gesso dentro dos tratamentos sem calcário e com a aplicação de $2.700 \mathrm{~kg} \mathrm{ha}^{-1}$ de calcário. As doses de calcário foram avaliadas mediante análise de regressão dentro de cada tratamento com gesso. Foram feitas análises de correlação linear simples entre os dados de Ca e Mg trocáveis, extraídos por resina trocadora de íons e os extraídos por percolação com solução de KCl, para cada profundidade, visando verificar a similaridade entre os métodos.

\section{RESULTADOS E DISCUSSÃO}

Observou-se que em todas as profundidades, com destaque para as mais profundas $(>0,10 \mathrm{~m})$, os teores de Ca não-trocável foram menores que os trocáveis, indicando que a dissolução dos corretivos foi rápida (Figura 1). Isso se deve ao fato de que, considerando o PN de 84,3 \% e PRNT de 71,2 \%, 84,5 \% do calcário utilizado apresentava granulometria suficientemente fina para reagir no solo, dentro de um período de dois anos. Pandolfo \& Tedesco (1996) observaram que num Argissolo Vermelho distrófico as partículas de diâmetro entre 0,10 e 0,25 e 0,84 e 2,00 $\mathrm{mm}$ apresentaram estabilização dos valores de $\mathrm{pH}$ aos seis e 42 meses, respectivamente. Raij et al. (1996) verificaram que 14 meses após a incorporação, dependendo da dose, entre 21 e $36 \%$ de calcário com PRNT de $59 \%$ e $52 \%$ das partículas maiores que $0,30 \mathrm{~mm}$ ainda não haviam sido dissolvidos. Para Mello et al. (2003), mesmo quando aplicado em superfície, a maior parte da fração granulométrica mais fina (menor que $0,30 \mathrm{~mm}$ ) do calcário reage no solo em três meses, enquanto a fração com maior dimensão $(0,84-2,0 \mathrm{~mm})$ continua reagindo posteriormente. Segundo Quaggio et al. (1995), um calcário tradicional, com cerca de $25 \%$ de suas partículas maiores que a peneira de $0,30 \mathrm{~mm}$, sempre proporcionou maiores valores de Ca e Mg não-trocáveis no solo; de 6 para 20 meses após aplicação, a diferença ficou ainda maior em comparação com um calcário de granulometria mais fina ("filler").

A calagem elevou os teores de Ca trocável, extraído por meio da resina e da percolação com solução de $\mathrm{KCl}$, nas camadas superficiais do solo (0-0,10 m) tanto

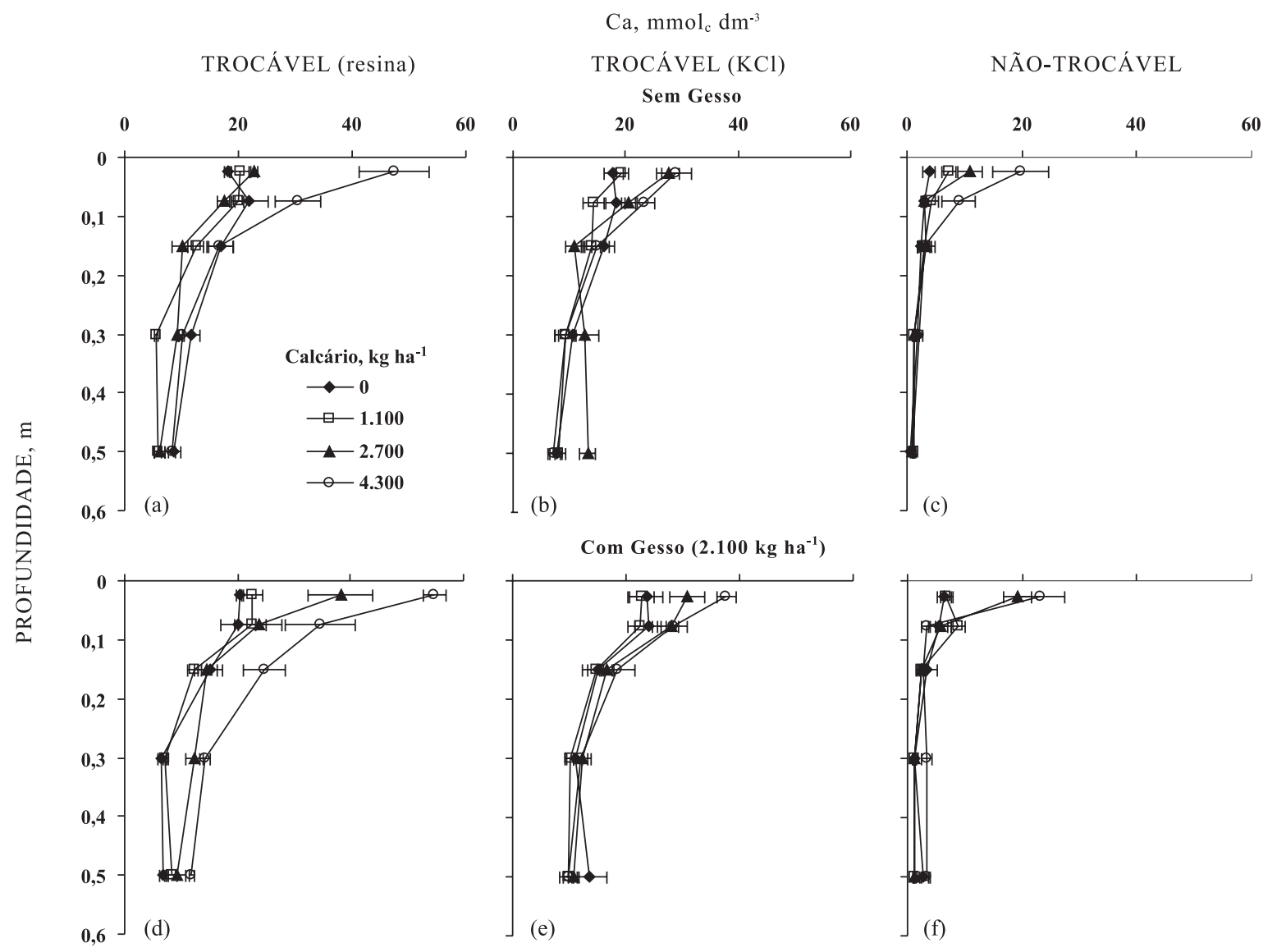

Figura 1. Teores de cálcio trocável, extraído por resina trocadora de íons (a, d) e percolação com solução de $\mathrm{KCl}(\mathrm{b}, \mathrm{e})$, e não-trocável (c, f) em um Latossolo Vermelho distroférrico, 18 meses após a aplicação superficial de doses de calcário, sem e com a aplicação de gesso. Barras horizontais referem-se ao desvio-padrão das médias. 
na presença quanto na ausência da aplicação de gesso (Figura 1a,b,d,e). A aplicação das maiores doses de calcário (2.700 e $4.300 \mathrm{~kg} \mathrm{ha}^{-1}$ ) em superfície, tanto na presença quanto na ausência de gesso, promoveu aumento no teor de Ca não-trocável apenas na camada superficial do solo $(0-0,05 \mathrm{~m})$. Isso indica que praticamente não houve movimentação física de partículas do calcário no perfil do solo, ou, se houve, após atingirem as camadas mais profundas (>0,05 m), essas partículas foram dissolvidas, provavelmente devido à maior acidez nessas camadas. Em sistema plantio direto há movimento de partículas finas de calcário $(<15 \mu \mathrm{m})$, mediante a percolação de água por meio de planos de fraqueza (Petrere \& Anghinoni, 2001; Amaral et al., 2004), ou canais formados por raízes mortas, mantidos intactos em razão da ausência de preparo convencional do solo (Oliveira \& Pavan, 1996; Petrere \& Anghinoni, 2001; Amaral et al., 2004). A maior acidez do solo pode aumentar o gradiente de difusão de íons alcalinos a partir do grânulo de calcário, favorecendo a dissolução deste (Pandolfo \& Tedesco, 1996).

Os valores de Ca trocável extraído por percolação com solução de $\mathrm{KCl}$, especialmente quando da aplicação da maior dose de calcário (4.300 kg ha-1), são inferiores aos obtidos mediante o uso da resina trocadora de íons (Figura 1a,b,d,e). Esses resultados indicam que a resina trocadora de íons pode estar superestimando os teores de Ca trocável no solo. No entanto, existe alta correlação entre eles (Quadro 2). Esses resultados estão de acordo com os relatados por Lima (2004), que encontraram alta correlação positiva entre os valores de Ca e Mg extraídos pela percolação com solução de $\mathrm{KCl}$ e pela resina. No processo de extração pela resina, devido à ação física da esfera de vidro, pode ocorrer fragmentação de partículas de calcário de maior dimensão (> 0,30 mm), aumentando a superfície de contato destas com a solução, ou, devido ao longo tempo de agitação (16 horas), pode ocorrer dissolução de frações do corretivo que ainda se encontravam sem

Quadro 2. Coeficientes de correlação simples (r) entre os teores de cálcio e magnésio trocáveis extraídos por percolação com solução de $\mathrm{KCl}$ e os extraídos por resina trocadora de íons

\section{Profundidade Ca trocável Mg trocável}

\begin{tabular}{cll}
\hline $\mathrm{m}$ & & \\
$0-0,05$ & $0,78^{* * *}$ & $0,81^{* * *}$ \\
$0,05-0,10$ & $0,69^{* * *}$ & $0,73^{* * *}$ \\
$0,10-0,20$ & $0,78^{* * *}$ & $0,62^{* * *}$ \\
$0,20-0,40$ & $0,35^{*}$ & $0,59^{* * *}$ \\
$0,40-0,60$ & $-0,03$ & $0,38^{*}$ \\
\hline
\end{tabular}

* e *** indicam significância estatística a 5 e $0,1 \%$ elo teste $t$, respectivamente. reagir no solo e, conseqüentemente, superestimar o teor de Ca trocável. Assim, os resultados indicam que a extração utilizando percolação com solução de $\mathrm{KCl}$, ou mesmo a extração com KCl (Raij et al., 2001), podem ser mais coerentes para a determinação do Ca trocável em solos onde recentemente foram aplicados corretivos em superfície, necessitando, porém, de maiores estudos a esse respeito.

Como o calcário, o gesso também contribuiu para a elevação dos teores de Ca trocável, principalmente nas camadas superficiais do solo (Figura 2a,b,d,e). A aplicação de gesso não teve efeito significativo sobre os teores de Ca não-trocável, na ausência da aplicação de calcário (Figura 2c), provavelmente pelo fato de o gesso ser mais solúvel e então ter se solubilizado em curto período de tempo quando aplicado ao solo, fazendo com que 18 meses após a aplicação em superfície praticamente não houvesse mais residual de gesso no solo. Contudo, na presença de calcário, o gesso proporcionou maior teor de Ca não-trocável na camada superficial (0-0,10 m) (Figura 2f). Esse efeito pode ser decorrente da maior solubilidade do gesso, em relação ao calcário, e da presença de um ânion estável $\left(\mathrm{SO}_{4}{ }^{2-}\right)$, que podem ter contribuído para que a aplicação de gesso em combinação com calcário promovesse elevação dos valores de $\mathrm{pH}$ nessa camada mais rapidamente do que nos tratamentos que receberam apenas calcário (Quadro 3). O ânion $\mathrm{SO}_{4}{ }^{2-}$, quando absorvido ativamente pelas plantas, faz com que estas aumentem na solução do solo a concentração de $\mathrm{OH}^{-}$ (Malavolta et al., 1997), reduzindo, com isso, a acidez. Além disso, pode ter ocorrido a liberação de $\mathrm{OH}^{-}$pelo $\mathrm{SO}_{4}{ }^{2-}$, mediante troca de ligantes, com a formação de estruturas hidroxiladas de $\mathrm{Al}$ - mecanismo chamado por Reeve \& Sumner (1972) de "autocalagem". Assim, a aplicação de gesso em superfície, provavelmente, reduziu a dissolução do calcário, pois o $\mathrm{pH}$ na camada superficial era maior. Sumner et al. (1986) e Oliveira \& Pavan (1996) relataram aumento nos valores de $\mathrm{pH}$ em decorrência da aplicação de gesso. Esse fato pode ser importante, já que, pelos resultados, pode-se inferir que a aplicação de gesso em superfície, simultaneamente à de calcário, pode reduzir a dissolução deste.

Quanto ao Mg, também foram verificados maiores teores trocáveis do que não-trocáveis nas camadas mais profundas do solo (Figura 3). Isso se deve ao processo de lixiviação dos produtos da dissolução do calcário (Caires et al., 1998) e ao reduzido movimento de partículas deste, como discutido anteriormente. Resultado semelhante foi observado por Lima (2004). A calagem proporcionou aumento nos teores de $\mathrm{Mg}$ trocável e não-trocável até a camada de 0-0,10 m de profundidade (Figura 3).

A aplicação de gesso proporcionou lixiviação de $\mathrm{Mg}$, reduzindo os teores trocáveis desse elemento, principalmente nas camadas superficiais do solo, e de forma mais evidente na ausência de calagem (Figura 4). Contudo, houve divergência entre os 
métodos de extração. A extração por resina demonstrou menores teores de $\mathrm{Mg}$ trocável com aplicação de gesso, na ausência de calcário, apenas nas camadas de 0,05-0,10 e 0,20-0,40 m; já a percolação com solução de $\mathrm{KCl}$ indicou menores teores na camada de 0-0,10 m (Figura $4 \mathrm{a}, \mathrm{b}$ ). Na presença de calagem, o método da resina extraiu menor teor de Mg trocável apenas na camada de 0,10-0,20 m, e o da percolação com $\mathrm{KCl}$, apenas nas camadas de 0-0,05 e 0,40-0,60 m (Figura 4d,e). Entretanto, é importante notar que os efeitos do gesso na redução dos teores de Mg foram maiores na ausência da aplicação de calcário. Mesmo tendo reduzido os teores de Mg trocável nas camadas superficiais do solo, não foi notado aumento dos teores desse elemento nas camadas mais profundas (0,40-0,60 m), provavelmente porque aos 18 meses após a aplicação do gesso o Mg já havia sido lixiviado para profundidades maiores que as amostradas. Caires et al. $(2001,2002)$ também constataram redução dos teores de $\mathrm{Mg}$ nas camadas superficiais do solo mediante a aplicação de gesso em superfície.

A aplicação de gesso não interferiu significativamente nos teores de $\mathrm{Mg}$ não-trocáveis, na ausência da calagem (Figura 4c). Contudo, promoveu aumento do valor dessa variável na camada de 0-0,05 m quando na presença da aplicação de calcário em superfície (Figura 4f). Esses resultados indicam que a aplicação de gesso interferiu na dissolução do calcário provavelmente devido ao aumento do $\mathrm{pH}$ na camada superficial do solo (Quadro 3), semelhante ao observado para o Ca.

Os teores de Mg trocável extraídos por percolação com solução de $\mathrm{KCl}$ apresentaram alta correlação com os determinados por meio da resina trocadora de íons (Quadro 2), o que corrobora os resultados obtidos por Lima (2004). No entanto, assim como observado para o Ca, os teores de $\mathrm{Mg}$ extraídos pela resina, nos tratamentos que receberam as maiores doses de calcário, foram maiores que os extraídos pelo método da percolação com solução de $\mathrm{KCl}$ (Figuras 1 e 2). Pelos resultados observados, é possível inferir que em áreas onde houve recente aplicação de doses elevadas de calcário em superfície, sem incorporação, o método da resina superestimou os teores de $\mathrm{Mg}$ trocáveis.

No presente trabalho (Figuras 1c, 2c, 3c, 4c) foram encontradas pequenos teores de $\mathrm{Ca}$ e $\mathrm{Mg}$ não-trocáveis onde não havia sido realizada a aplicação de corretivos, o que pode ser proveniente de minerais ainda não

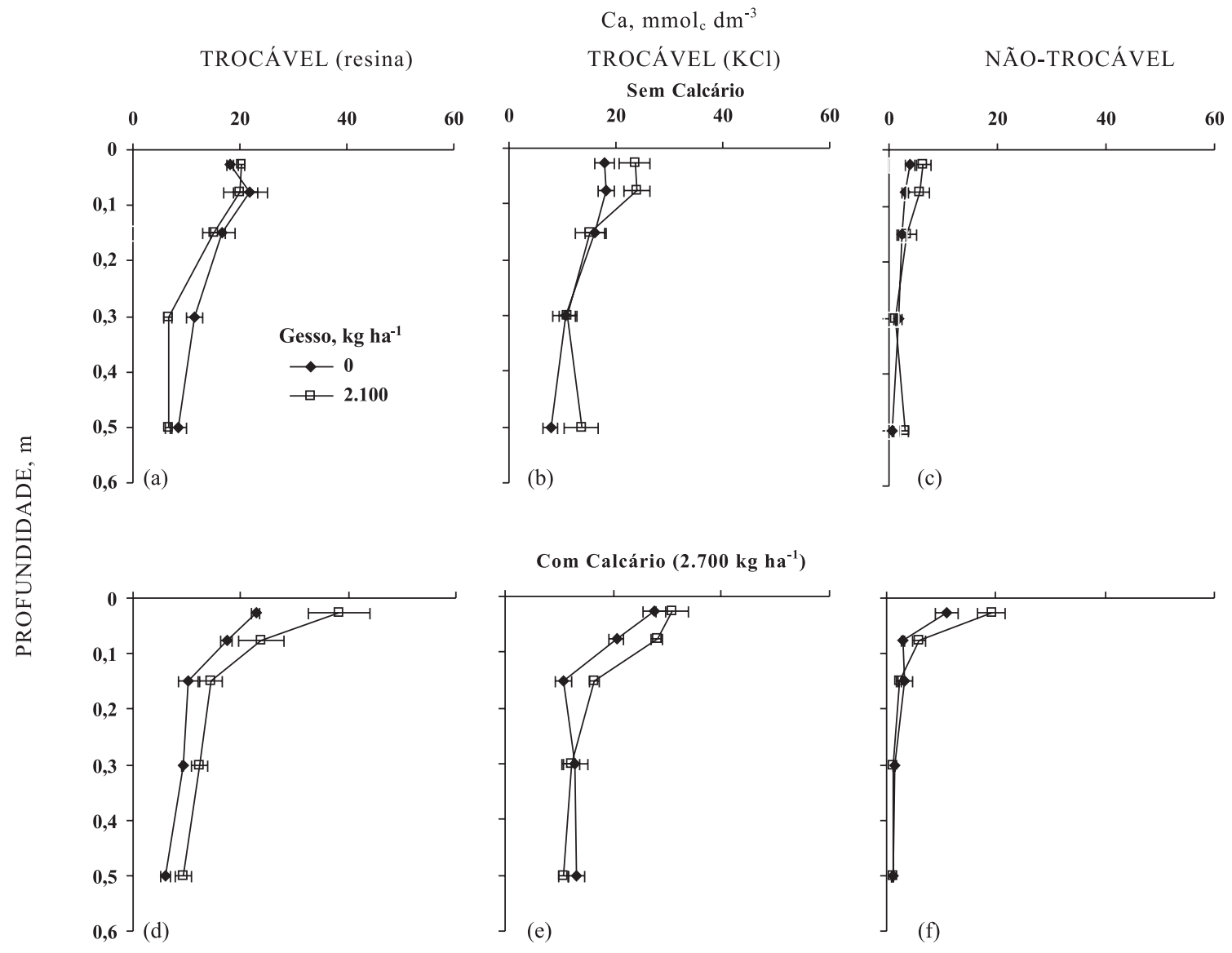

Figura 2. Teores de cálcio trocável, extraído por resina trocadora de íons (a, d) e percolação com solução de KCl (b, e), e não-trocável (c, f) em um Latossolo Vermelho distroférrico, 18 meses após a aplicação de gesso, sem e com a aplicação superficial de calcário. Barras horizontais referem-se ao desvio-padrão das médias. 
Quadro 3. Valores de pH $\mathrm{CaCl}_{2}$ em um Latossolo Vermelho distroférrico, 18 meses após a aplicação superficial de doses de calcário, sem e com a aplicação de gesso

\begin{tabular}{|c|c|c|c|c|c|}
\hline \multirow[b]{2}{*}{ Profundidade } & \multirow[b]{2}{*}{ Gesso } & \multicolumn{4}{|c|}{ Calcário $\left(\mathrm{kg} \mathrm{ha}^{-1}\right)$} \\
\hline & & $\mathbf{0}$ & 1.100 & 2.700 & 4.300 \\
\hline $\mathrm{m}$ & $\mathrm{kg} \mathrm{ha}^{-1}$ & - & 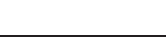 & 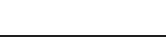 & 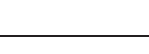 \\
\hline $0-0,05$ & $\begin{array}{r}0 \\
2.100\end{array}$ & $\begin{array}{l}4,6 \pm 0,11^{(1)} \\
4,8 \pm 0,07\end{array}$ & $\begin{array}{l}4,8 \pm 0,10 \\
5,0 \pm 0,16\end{array}$ & $\begin{array}{l}5,3 \pm 0,15 \\
5,7 \pm 0,12\end{array}$ & $\begin{array}{l}5,7 \pm 0,23 \\
5,8 \pm 0,20\end{array}$ \\
\hline $0,05-0,10$ & $\begin{array}{r}0 \\
2.100\end{array}$ & $\begin{array}{l}4,6 \pm 0,14 \\
4,8 \pm 0,12\end{array}$ & $\begin{array}{l}4,6 \pm 0,11 \\
4,9 \pm 0,13\end{array}$ & $\begin{array}{l}4,9 \pm 0,11 \\
5,1 \pm 0,14\end{array}$ & $\begin{array}{l}5,3 \pm 0,27 \\
5,3 \pm 0,17\end{array}$ \\
\hline $0,10-0,20$ & $\begin{array}{r}0 \\
2.100\end{array}$ & $\begin{array}{l}4,5 \pm 0,16 \\
4,6 \pm 0,26\end{array}$ & $\begin{array}{l}4,4 \pm 0,10 \\
4,6 \pm 0,05\end{array}$ & $\begin{array}{l}4,5 \pm 0,19 \\
4,6 \pm 0,10\end{array}$ & $\begin{array}{l}4,8 \pm 0,10 \\
4,8 \pm 0,19\end{array}$ \\
\hline $0,20-0,40$ & $\begin{array}{r}0 \\
2.100\end{array}$ & $\begin{array}{l}4,2 \pm 0,14 \\
4,2 \pm 0,11\end{array}$ & $\begin{array}{l}4,2 \pm 0,08 \\
4,2 \pm 0,07\end{array}$ & $\begin{array}{l}4,2 \pm 0,08 \\
4,2 \pm 0,26\end{array}$ & $\begin{array}{l}4,1 \pm 0,07 \\
4,3 \pm 0,08\end{array}$ \\
\hline $0,40-0,60$ & $\begin{array}{r}0 \\
2.100\end{array}$ & $\begin{array}{l}4,0 \pm 0,05 \\
4,2 \pm 0,14\end{array}$ & $\begin{array}{l}3,9 \pm 0,04 \\
4,0 \pm 0,06\end{array}$ & $\begin{array}{l}4,0 \pm 0,03 \\
3,8 \pm 0,03\end{array}$ & $\begin{array}{l}4,0 \pm 0,02 \\
4,0 \pm 0,08\end{array}$ \\
\hline
\end{tabular}

(1) Os números representam: média \pm desvio-padrão.

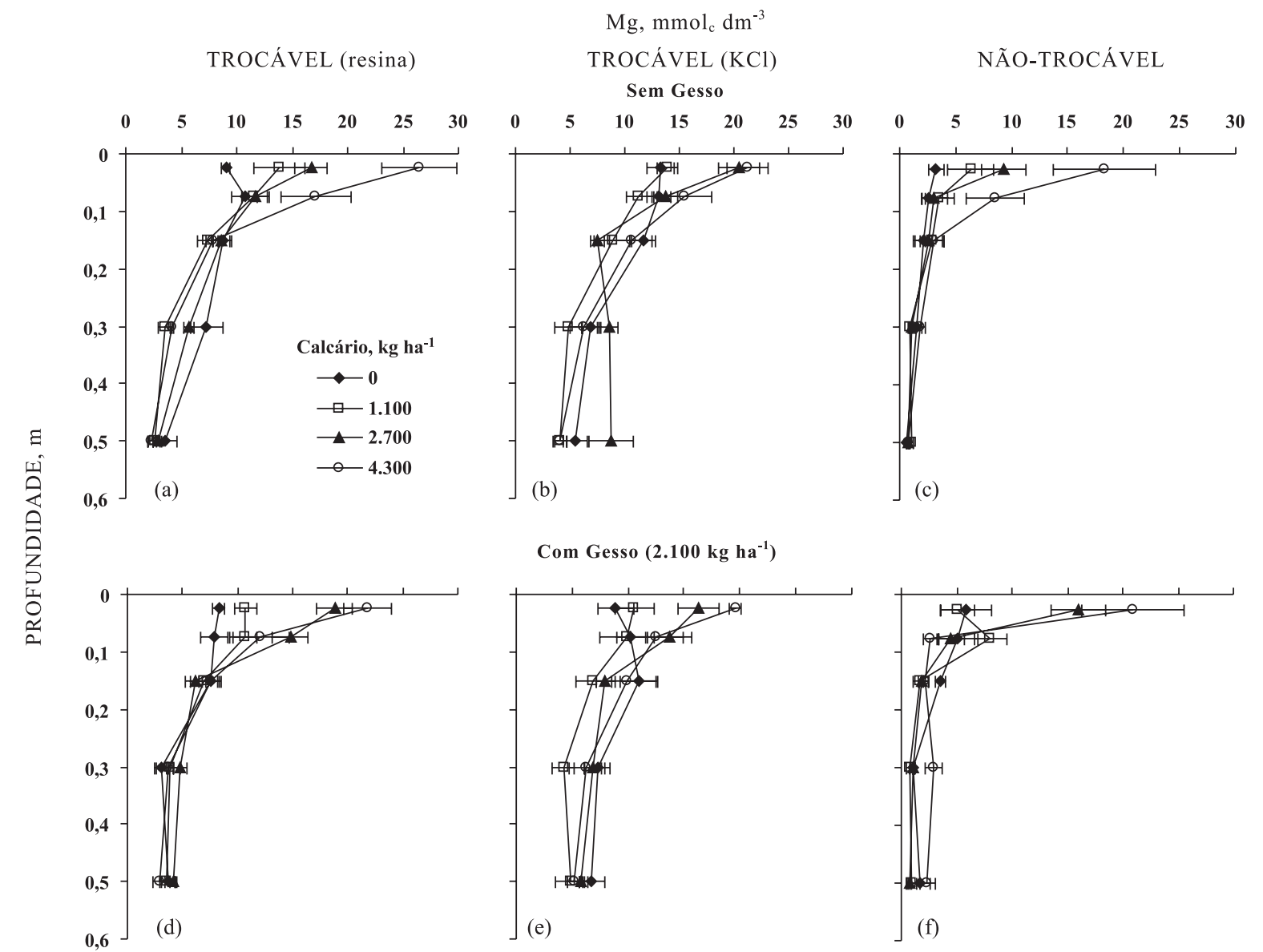

Figura 3. Teores de magnésio trocável, extraído por resina trocadora de íons (a, d) e percolação com solução de KCl (b, e), e não-trocável (c, f) em um Latossolo Vermelho distroférrico, 18 meses após a aplicação superficial de doses de calcário, sem e com a aplicação de gesso. Barras horizontais referem-se ao desvio-padrão das médias. 


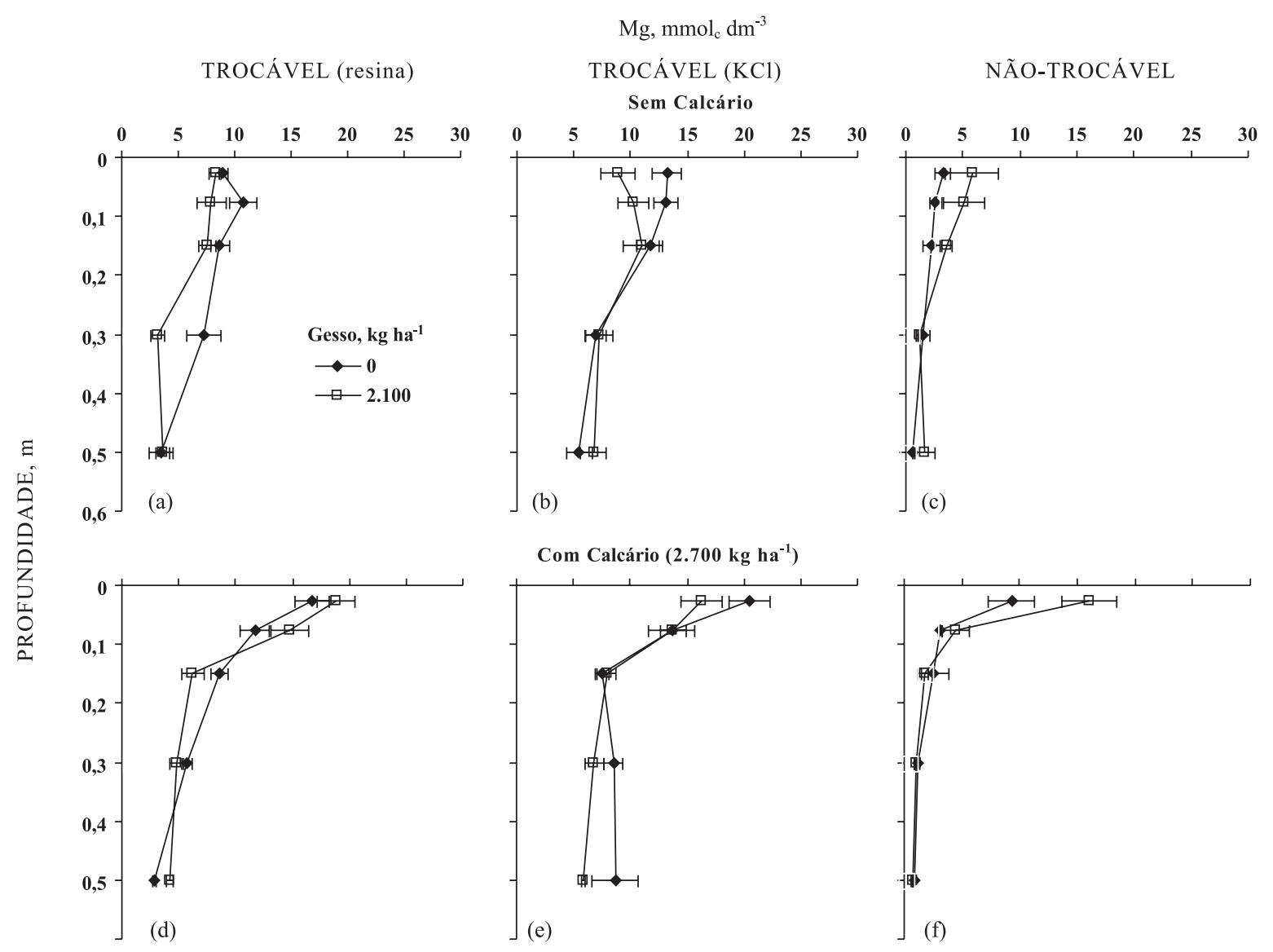

Figura 4. Teores de magnésio trocável, extraído por resina trocadora de íons (a, d) e percolação com solução de KCl (b, e), e não-trocável (c, f) em um Latossolo Vermelho distroférrico, 18 meses após a aplicação de gesso, sem e com a aplicação superficial de calcário. Barras horizontais referem-se ao desvio-padrão das médias.

totalmente intemperizados, que contenham $\mathrm{Ca}$ e $\mathrm{Mg}$ na sua estrutura, ou de partículas grosseiras provenientes de calagens de longa data. Resultados semelhantes foram obtidos por Raij et al. (1982), Quaggio et al. (1982) e Quaggio et al. (1995).

Os maiores teores de $\mathrm{Ca}$ e $\mathrm{Mg}$ não-trocáveis na camada superficial $(0-0,10 \mathrm{~m})$ do solo nos tratamentos que receberam as maiores doses de calcário (2.700 e $4.300 \mathrm{~kg} \mathrm{ha}^{-1}$ ) demonstram que havia calcário por reagir nessa camada, pois, com base nos teores de $\mathrm{Ca}$ não-trocável na camada de $0-0,05 \mathrm{~m}$ dos tratamentos que não receberam gesso (Figura 1c), nas características do calcário e descontados $228 \mathrm{~kg} \mathrm{ha}^{-1}$ do tratamento testemunha, verifica-se que ainda havia 198, 430 e $943 \mathrm{~kg} \mathrm{ha}^{-1}$ de calcário sem reagir, respectivamente, nas doses de $1.100,2.700$ e $4.300 \mathrm{~kg} \mathrm{ha}^{-1} \mathrm{de}$ calcário. Já nos tratamentos que receberam gesso (Figura 1f), descontando $381 \mathrm{~kg} \mathrm{ha}^{-1}$ do tratamento sem calcário, ainda havia 24, 763 e $1.005 \mathrm{~kg} \mathrm{ha}^{-1} \mathrm{sem}$ reagir, respectivamente, para as doses de 1.100, 2.700 e $4.300 \mathrm{~kg} \mathrm{ha}^{-1}$ de calcário. Em razão desses resultados, constata-se que o método do "calcário residual" pode proporcionar boa estimativa da quantidade de calcário ainda remanescente no solo, confirmando os resultados de Raij et al. (1982), Quaggio et al. (1982) e Quaggio et al. (1995).

Dessa forma, assim como citado por Lima (2004), a determinação das frações não-trocáveis de $\mathrm{Ca}$ e Mg, aliada às características químicas apresentadas na análise de fertilidade do solo (pH e saturação por bases), podem auxiliar na definição do momento em que se faz necessária a reaplicação de calcário em área onde foi realizada implantação do sistema plantio direto com calagem em superfície, sem incorporação.

\section{CONCLUSÕES}

1. Houve alta correlação na determinação de Ca e $\mathrm{Mg}$ trocável entre os métodos de percolação com solução de $\mathrm{KCl}$ e resina trocadora de íons.

2. A extração pelo método da resina superestimou os teores de $\mathrm{Ca}$ e $\mathrm{Mg}$ trocáveis em solo com recente aplicação de calcário em superfície. 
3. A aplicação de gesso em superfície reduziu a dissolução do calcário na camada superficial $(0-0,10 \mathrm{~m})$.

4. Os teores de Ca e Mg não-trocáveis podem ser utilizados para estimar a quantidade de calcário remanescente no solo.

\section{AGRADECIMENTOS}

À Fapesp, pela concessão de bolsa de doutorado ao primeiro autor.

\section{LITERATURA CITADA}

AMARAL, A.S. \& ANGHINONI, I. . Alteração de parâmetros químicos do solo pela reaplicação superficial de calcário no sistema plantio direto. Pesq. Agropec. Bras., 36:695$702,2001$.

AMARAL, A.S.; ANGHINONI, I.; HENRICHIS, R. \& BERTOL, I. Movimentação de partículas de calcário no perfil de um Cambissolo em plantio direto. R. Bras. Ci. Solo, 28:359367, 2004.

BALBINO, L.C.; MOREIRA, J.A.A.; SILVA, J.G.; OLIVEIRA, E.F. \& OLIVEIRA, I.P. Plantio direto. In: ARAUJO, R.S.; RAVA, C.A.; STONE, L.F. \& ZIMMERMANN, M.J.O., coords. Cultura do feijoeiro comum no Brasil. Piracicaba, Potafós, 1996. p.301-352.

BARIZON, R.R.M. Calagem na superfície para a cultura da soja, em semeadura direta sobre Brachiaria brizantha. Botucatu,Faculdade de Ciências Agronômicas, Universidade Estadual Paulista, Botucatu, 2001. 88p. (Tese de Mestrado)

CAIRES, E.F. \& FONSECA, A.F. Absorção de nutrientes pela soja cultivada no sistema de plantio direto em função de calagem na superfície. Bragantia, 59:213-220, 2000.

CAIRES, E.F.; ALLEONI, L.R.F.; CAMBRI, M.A. \& BARTH, G. Surface application of lime for crop grain production under a no-till system. Agron. J., 97:791-798, 2005.

CAIRES, E.F.; BANZATTO, D.A. \& FONSECA, A.F. Calagem na superfície em sistema plantio direto. R. Bras. Ci. Solo, 24:161-169, 2000.

CAIRES, E.F.; BLUM, J.; BARTH, G.; GARBUIO, F.J. \& KUSMAN, M.T. Alterações químicas do solo e resposta da soja ao calcário e gesso aplicados na implantação do sistema de plantio direto. R. Bras. Ci. Solo, 27:275-286, 2003.

CAIRES, E.F.; CHUEIRI, W.A.; MADRUGA, E.F. \& FIGUEIREDO, A. Alterações de características químicas do solo e resposta da soja ao calcário e gesso aplicados na superfície em sistema de cultivo sem preparo de solo. R. Bras. Ci. Solo, 22:, p.27-34, 1998.

CAIRES, E.F.; FELDHAUS, I.C. \& BLUM, J. Crescimento radicular e nutrição da cevada em função da calagem e aplicação de gesso. Bragantia, 60:213-223, 2001.
CAIRES, E.F.; FELDHAUS, I.C.; BARTH, G. \& GARBUIO, F.J. Lime and gypsum application on the wheat crop. Sci. Agric., 59:357-364, 2002.

CAIRES, E.F.; FONSECA, A.F.; MENDES, J.; CHUEIRI, W. \& MADRUGA, E.F. Produção de milho, trigo e soja em função das alterações das características químicas do solo pela aplicação de calcário e gesso na superfície, em sistema de plantio direto. R. Bras. Ci. Solo, 23:315-327, 1999.

COMISSÃO DE FERTILIDADE DO SOLO DO ESTADO DE MINAS GERAIS - CFSEMG. Recomendações para uso de corretivos e fertilizantes em Minas Gerais: $5^{\text {a }}$ aproximação. Viçosa, MG, 1999. 360p.

COMISSÃO DE QUÍMICA E FERTILIDADE DO SOLO CQFS RS/SC. Manual de adubação e calagem para os estados do Rio Grande do Sul e Santa Catarina. Porto Alegre, Sociedade Brasileira de Ciência do Solo - Núcleo Regional Sul, 2004. 400p.

EMPRESA BRASILEIRA DE PESQUISA AGROPECUÁRIA EMBRAPA. Centro Nacional de Pesquisa de Solos. Manual de métodos de análise de solo. 2.ed. Brasília, Embrapa-CNPS, 1997. 212p. (Documentos, 1)

LIMA, E.V. Plantas de cobertura e calagem superficial na fase de implantação do sistema de plantio direto em região de inverno seco. Botucatu, Faculdade de Ciências Agronômicas, Universidade Estadual Paulista, 2004. 125p. (Tese de Doutorado)

MALAVOLTA, E.; VITTI, G.C. \& OLIVEIRA, S.A. Avaliação do estado nutricional de plantas: Princípios e aplicações. 2.ed. Piracicaba, Potafos, 1997. 319p.

MELLO, J.C.A.; VILLAS BÔAS, R.L.; LIMA, E.V.; CRUSCIOL, C.A.C. \& BÜLL, L.T. Alterações nos atributos químicos de um Latossolo distroférrico decorrentes da granulometria e doses de calcário em sistemas plantio direto e convencional. R. Bras. Ci. Solo, 27:553-561, 2003.

MIRANDA, L.N.; MIRANDA, J.C.C.; REIN, T.A. \& GOMES, A.C. Utilização de calcário em plantio direto e convencional de soja e milho em Latossolo Vermelho. Pesq. Agropec. Bras., 40:563-572, 2005.

MIYAZAWA, M.; PAVAN, M.A. \& FRANCHINI, J.C. Neutralização da acidez do perfil do solo por resíduos vegetais. Infor. Agron., 92:1-8, 2000.

MUZILLI, O. Princípios e perspectivas de expansão. In: INSTITUTO AGRONOMICO DO PARANÁ. Plantio direto no estado do Paraná. Londrina, 1981. p.11-16 (Circular, 23)

NOLLA, A. \& ANGHINONI, I. Critérios de calagem para a soja no sistema plantio direto consolidado. R. Bras. Ci. Solo, 30:475-483. , 2006.

NOLLA, A. \& ANGHINONI, I. Métodos utilizados para a correção da acidez do solo no Brasil. R. Ci. Exatas Nat., 6:97-111, 2004.

NOLLA, A.; SCHLINDWEIN, J.A.; AMARAL. A.S. \& ANGHINONI, I. Indicadores para a tomada de decisão de calagem no sistema plantio direto. R. Bras. Agroci., 11:471476, 2005.

OLIVEIRA, E. L. \& PAVAN, M. A. Control of soil acidity in notillage system for soybean production. Soil Till. Res., 38:4757, 1996. 
PANDOLFO, C. M. \& TEDESCO, M. J. Eficiência relativa de frações granulométricas de calcário na correção da acidez do solo. Pesq. Agropec. Bras., 31:753-758, 1996.

PETRERE, C. \& ANGHINONI, I. Alteração de atributos químicos no perfil do solo pela calagem superficial em campo nativo. R. Bras. Ci. Solo, 25:885-895, 2001.

PÖTTKER, D. \& BEN, J.R. Calagem para uma rotação de culturas no plantio direto. R. Bras. Ci. Solo, 22:675-684, 1998.

QUAGGIO, J.A.; MASCARENHAS, H.A. \& BATAGLIA, O.C. Resposta da soja à aplicação de doses crescentes de calcário em Latossolo Roxo distrófico de cerrado. II - Efeito residual. R. Bras. Ci. Solo, 6:113-118, 1982.

QUAGGIO, J.A.; RAIJ, B. van; GALLO, P.B. \& MASCARENHAS, H.A.A. Agronomic efficiency of limestones with different acid-neutralizing capacity, under field condition. In: SYMPOSIUM ON PLANT-SOIL INTERATIONS AT LOW pH, 3., 1995, Brisbane. Proceeding. Dordrecht, Kluwer Academic Publishers, 1995. p.491-496.

RAIJ, B. van; ANDRADE, J.C.; CANTARELLA, H. \& QUAGGIO, J.A. Análise química para avaliação da fertilidade de solos tropicais. Campinas, Instituto Agronômico, 2001. 284p.
RAIJ, B. van; CANTARELLA, H. \& FURLANI, P.R. Efeito, na reação do solo, da absorção de amônio e nitrato pelo sorgo, na presença e na ausência de gesso. R. Bras. Ci. Solo, 12:131-136, 1988.

RAIJ, B. van; CANTARELLA, H.; CAMARGO, A.P. \& SOARES, E. Perdas de cálcio e magnésio durante cinco anos em ensaio de calagem. R. Bras. Ci. Solo, 6:33-37, 1982.

RAIJ, B. van; CANTARELLA, H.; QUAGGIO, J.A. \& FURLANI, A.M.C., eds. Recomendações de adubação e calagem para o Estado de São Paulo. Campinas, Instituto Agronômico, 1996. 285p.

REEVE, N.G. \& SUMNER, M.E. Amelioration of subsoil acidity in Natal Oxisols by leaching of surface-applied amendments. Agrochemophysica, 4:1-6, 1972.

SORATTO, R.P. Aplicação de calcário e gesso em superfície na implantação do sistema de plantio direto. Botucatu, Faculdade de Ciências Agronômicas, Universidade Estadual Paulista, 2005. 173p. (Tese de Doutorado)

SOUSA, D.M.G. \& LOBATO, E. Cerrado: Correção do solo e adubação. Brasília, Embrapa Informação Tecnológica, 2004. 416p.

SUMNER, M.E.; SHAHANDEH, H.; BOUTON, J \& HAMMEL, J. Amelioration of an acid soil prolife through deep liming and surface application of gypsum. Soil Sci. Soc. Am. J., 50:1254-1278, 1986. 